\title{
Rechtsbescherming
}

\section{Bescherming van het dierenwelzijn, de volksgezondheid of de godsdienstvrijheid?}

\author{
Het arrest Liga van Moskeeën over het ritueel slachten van dieren
}

\author{
Mr. dr. M. Beijer*
}

In het arrest Liga van Moskeeën buigt het Hof van Justitie zich voor het eerst over de Unierechtelijke eisen aan de (onverdoofde) rituele slacht van dieren. Een Belgische rechter had een prejudiciële vraag gesteld over de geldigheid van deze eisen gelet op de bescherming van de godsdienstvrijheid. Het Hof van Justitie concludeert in het arrest dat de godsdienstvrijheid niet wordt beperkt, en laat veel aandacht uitgaan naar de legitieme doelen die door de Unierechtelijke eisen worden nagestreefd, waaronder de bescherming van het dierenwelzijn en de volksgezondheid. Dit artikel bespreekt de bijzonderheden aan deze grondrechtelijke toetsing van het Hof van Justitie.

Hv7 29 mei 2018, zaak C-426/16, Liga van Moskeeёn en Islamitische Organisaties Provincie Antmerpen VZW e.a./ Vlaamse Gemest, ECLI:EU:C:2018:335.

\section{Inleiding}

Deze bijdrage gaat over het arrest van het Hof van Justitie in de zaak Liga van Moskeeën en Islamitische Organisaties Provincie Antwerpen VZW e.a. ${ }^{1}$ In deze zaak werd het Hof van Justitie gevraagd om de Unierechtelijke eisen aan de religieuze slachtmethode van dieren te toetsen aan de godsdienstvrijheid. Volgens het Hof van Justitie levert de eis dat dieren (altijd) in een erkend slachthuis moeten worden gedood geen beperking van de godsdienstvrijheid op. Deze bijdrage gaat nader in op de overwegingen die het Hof van Justitie tot deze conclusie brachten, en daarna wordt kort stilgestaan bij de betekenis van dit arrest voor de praktijk.

Mr. dr. M. (Malu) Beijer is verbonden aan de Radboud Universiteit Nijmegen als Research fellow.

1. HvJ 29 mei 2018, zaak C-426/16, Liga van Moskeeën en Islamitische Organisaties Provincie Antwerpen VZW e.a./Vlaamse Gewest, ECLI:EU:C:2018:335 (hierna: Liga van Moskeeën).
Het arrest raakt aan een gevoelige grondrechtelijke kwestie. ${ }^{2}$ Het onverdoofd slachten van dieren volgens religieuze riten vormt al langere tijd een onderwerp van discussie in België, maar ook in Nederland en in verschillende andere lidstaten. Welke nieuwe inzichten biedt het arrest Liga van Moskeeën voor die discussie? En om welke reden wordt deze grondrechtelijke kwestie nu eigenlijk door het Unierecht geregeld? Op deze vragen wordt in het slot van deze bijdrage nader ingegaan.

\section{Feiten en omstandigheden van de zaak}

De zaak Liga van Moskeeën en Islamitische Organisaties Provincie Antwerpen VZW e.a. speelt zich af in Vlaanderen. In 2014 besloot de nieuwe minister bevoegd voor Dierenwelzijn om niet langer toe te staan dat dieren tijdens het islamitisch offerfeest onverdoofd ritueel worden geslacht in tijdelijke slachtinrichtingen. Voorheen waren de tijdelijke slachtinrichtingen vanwege het gebrek aan capaciteit in de erkende slachthuizen rondom de periode van het islamitisch offerfeest, als gevolg van een (grote) stijging van vraag naar vlees dat aan de religieuze voorschriften voor slachting voldeed, nog wel toegestaan. Verordening (EG) nr. 1099/2009 inzake de bescherming van dieren bij doden stelt eisen aan de wij-

2. Over het dragen van religieuze symbolen op de werkvloer, discriminatie op grond van geloofsovertuiging in de sollicitatieprocedure, de bescherming van gegevens door geloofsgemeenschappen, en belastingvrijstellingen voor religieuze gebouwen heeft het Hof van Justitie al uitspraken gedaan, zie daarvoor HvJ 14 maart 2017, zaak C-157/15, Achbita/G4S Secure Solutions, ECLI:EU:C:2017:203; HvJ 14 maart 2017, zaak C-188/15, Bougnaoui en ADDH, ECLI:EU:C:2017:204; HvJ 17 april 2018, zaak C-414/16, Egenberger, ECLI:EU:C:2018:257; HvJ 10 juli 2018, zaak C-25/17, Tietosuojavaltuutettu, ECLI:EU:C:2018:551; en HvJ 27 juni 2017, zaak C-74/16, Congregación de Escuelas Pías, ECLI:EU:C:2017:496. 
ze waarop dieren worden geslacht. ${ }^{3}$ Deze gemeenschappelijke regels zijn opgesteld vanwege de verschillen in de wetgeving van de lidstaten over de bescherming van dieren bij doden, die niet alleen van invloed zijn op de mededinging tussen bedrijfsexploitanten, maar ook hebben geleid tot bezorgdheid over het dierenwelzijn. ${ }^{4}$ Deze verordening bevat in artikel 4 een verplichting om dieren te bedwelmen voordat zij worden gedood, maar maakt daarop een uitzondering indien dieren worden geslacht volgens speciale methoden die vereist zijn voor religieuze riten (in het vierde lid). In dat geval dient het slachten gelet op artikel 2 sub $\mathrm{k}$ van de verordening wel plaats te vinden in een erkend slachthuis dat aan de eisen van Verordening (EG) nr. 853/2004 voldoet. Deze verordening stelt strenge hygiënevoorschriften voor levensmiddelen van dierlijke oorsprong op, om schade aan de volksgezondheid te voorkomen. De tijdelijke slachtinrichtingen voldeden volgens de minister niet aan de vereisten van deze verordening. ${ }^{5}$

Vanwege het verbod op de tijdelijke slachtinrichtingen besloten verschillende moslimverenigingen en koepelorganisaties van moskeeën naar de rechter te stappen. Zij kwamen bij de Nederlandstalige rechtbank van eerste aanleg in Brussel terecht die besloot tot een prejudiciële verwijzing naar het Hof van Justitie. Deze rechtbank vroeg zich af of het vereiste in Verordening (EG) nr. 1099/2009 dat dieren enkel onverdoofd mogen worden geslacht in een erkend slachthuis, een schending van de godsdienstvrijheid oplevert. Dit grondrecht is neergelegd in artikel 9 van het Europees Verdrag voor de Rechten van de Mens (EVRM) en artikel 10 van het Handvest van de grondrechten van de EU (Handvest). Verder wees de verwijzende rechter op artikel 13 van het Werkingsverdrag van de EU (VWEU). Dit is een zogenoemde integratiebepaling die aan de Unie en de lidstaten de opdracht meegeeft om bij de uitvoering van het beleid van de Unie

'ten volle rekening [te houden] met hetgeen vereist is voor het welzijn van dieren als wezens met gevoel, onder eerbiediging van de wettelijke en bestuursrechtelijke bepalingen en gebruiken van de lidstaten met betrekking tot met name godsdienstige riten, culturele tradities en regionaal erfgoed'.

\section{Conclusie van de advocaat- generaal}

Advocaat-generaal Wahl concludeerde - kort samengevat - dat de speciale slachtmethoden die voor de religieuze riten vereist zijn binnen de werkingssfeer van de godsdienstvrijheid van artikel 10 van het Handvest vallen, maar dat geen sprake is van een beperking van dit grondrecht. De advocaat-generaal merkt hierbij op dat de betwisting van de geldigheid van de Unierechtelijke bepalingen in deze zaak 'minstens paradoxaal' is. ${ }^{6}$ Verordening (EG) nr. 1099/2009 steunt immers het onverdoofd ritueel slachten door een uitzondering te maken op de verplichting tot bedwelming van dieren voorafgaand aan de slacht. Daarbij worden geen aanvullende vereisten gesteld voor slachthuizen die rituele slachtmethoden toepassen. De verzoekers in deze zaak hebben verder, vanuit het oogpunt van de eerbiediging van de vrijheid van godsdienst, geen principiële redenen angevoerd waarom de Unierechtelijke eisen aan slachthuizen problematisch voor hen zouden zijn. ${ }^{7}$ Volgens de advocaat-generaal is er dus geen sprake van een beperking van de godsdienstvrijheid en draait deze zaak meer om conjuncturele problemen van de slachtcapaciteit die een samenloop van verschillende bijzondere omstandigheden laten zien en losstaan van de werkingssfeer van Verordening (EG) nr. 1099/2009. ${ }^{8}$ Indien het Hof van Justitie echter wel een beperking zou aannemen, dan zou daar volgens de advocaat-generaal geen rechtvaardiging voor kunnen worden geboden. Dat het gebruikmaken van een erkend slachthuis een meerwaarde biedt voor de bevordering van het dierenwelzijn, evenals de volksgezondheid, ten opzichte van het gebruikmaken van een tijdelijke slachtinrichting is namelijk niet vast komen te staan. Het is niet uitgesloten dat een onverdoofde slachting die onder goede omstandigheden is uitgevoerd minder pijnlijk kan zijn voor dieren dan een slachting met voorafgaande verdoving, gelet op de stress en het lijden van dieren dat wordt verergerd door de sterke industrialisering in deze sector. Daarnaast zouden volgens de advocaat-generaal ook andere maatregelen kunnen worden genomen die minder belastend zijn dan het beperken van de slacht van dieren tot erkende slachthuizen. ${ }^{9}$ Een beperking zou volgens de advocaat-generaal dus niet evenredig zijn aan het nastreven van de doelstellingen van het dierenwelzijn en de bescherming van de volksgezondheid, en zou daarmee niet gerechtvaardigd kunnen worden.
3. Verordening (EG) nr. 1099/2009 van de Raad van 24 september 2009 inzake de bescherming van dieren bij het doden, PbEU 2009, L 303/1. Uit een audit van de Europese Commissie, waarvan het eindrapport in 2015 werd gepubliceerd, was ook naar voren gekomen dat de tijdelijke slachtinrichtingen niet aan de vereisten voldeden. Zie daarover de Conclusie van de A-G van 30 november 2017 inzake C-426/16, Liga van Moskeeën, ECLI:EU:C:2017:926, punten 116-117.

4. Overweging 3 van Verordening (EG) nr. 1099/2009.

5. Deze eisen zijn opgenomen in Verordening (EG) nr. 853/2004 van het Europees Parlement en de Raad van 29 april 2004 houdende vaststelling van specifieke hygiënevoorschriften voor levensmiddelen van dierlijke oorsprong, PbEU 2004, L 139/55. 


\section{De uitspraak van het Hof van Justitie}

Ook het Hof van Justitie komt tot het oordeel dat de speciale methoden die vereist zijn voor religieuze riten binnen de werkingssfeer vallen van de godsdienstvrijheid van artikel 10 van het Handvest, en van artikel 4 lid 4 van Verordening (EG) nr. 1099/2009. Net als de advocaat-generaal komt het Hof van Justitie daarna tot de conclusie dat geen sprake is van een beperking van de godsdienstvrijheid. Het Hof van Justitie stelt voorop dat de uitzondering die de verordening maakt voor rituele slachtingen 'juist uitdrukking geeft aan het positieve streven van de Uniewetgever om het slachten van dieren zonder voorafgaande verdoving mogelijk te maken, zodat de vrijheid van godsdienst, in het bijzonder die van praktiserende moslims, tijdens het Offerfeest daadwerkelijk wordt geëerbiedigd' ${ }^{10}$ Verder beoogt de verordening volgens het Hof van Justitie uitsluitend 'het vrij verrichten van slachtingen zonder voorafgaande verdoving voor religieuze doeleinden te organiseren en hiervoor een technisch kader te scheppen'. ${ }^{11}$ Dit technische kader houdt op zichzelf gezien geen beperking van de godsdienstvrijheid in. Het Hof van Justitie wijst erop dat het om een niet-discriminerende maatregel gaat. Het vereiste van een erkend slachthuis is zonder onderscheid van toepassing op alle organisatoren van dierenslachtingen, ongeacht enig verband met een bepaalde godsdienst. ${ }^{12}$ Verder heeft de Uniewetgever de technische voorwaarden aan de erkende slachthuizen gesteld om de naleving van de voor de religieuze riten vereiste speciale slachtmethoden in overeenstemming te brengen met de essentiële regels van de twee verordeningen. De Uniewetgever heeft in verschillende overwegingen in Verordening (EG) nr. 1099/2009 er ook blijk van gegeven dat het alleen in een erkend slachthuis mogelijk is om het lijden van dieren zo veel mogelijk te beperken. ${ }^{13}$ Het Hof van Justitie merkt op dat de belangrijkste doelstelling die daarbij is nagestreefd de bescherming van het dierenwelzijn is. Hiernaast heeft de Uniewetgever met het vereiste beoogd een hoog niveau van de bescherming van de volksgezondheid na te streven. ${ }^{14}$

Het Hof van Justitie overweegt verder dat de problematiek die in de zaak voor de verwijzende rechter speelt maar een beperkt aantal gemeenten in Vlaanderen treft. ${ }^{15}$ De geldigheid van een bepaling van Unierecht kan niet afhankelijk worden gesteld van de bijzondere omstandigheden van een bepaald geval. De eventuele meerkosten die het oprichten van slachthuizen met zich meebrengt, vormen zuiver interne conjuncturele omstandigheden. ${ }^{16}$ Een korte en tijdelijke toename van

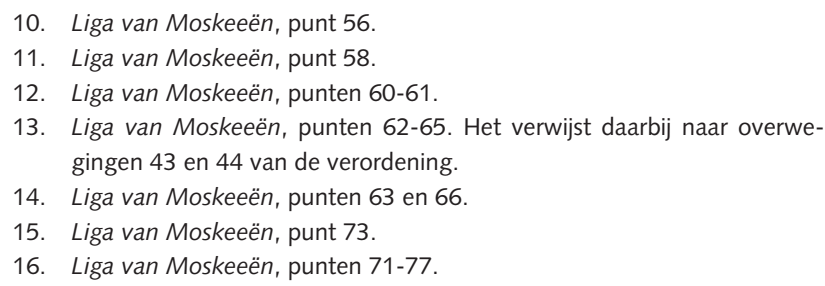

de vraag naar rituele slachtingen in het kader van het offerfeest kan volgens het Hof van Justitie de geldigheid van artikel 4 lid 4 Verordening (EG) nr. 1099/2009 niet aantasten. Het beroep op artikel 13 VWEU brengt daarin geen verandering. Niet duidelijk is immers welke Belgische wettelijke en bestuursrechtelijke bepalingen met betrekking tot godsdienstige riten geëerbiedigd zouden moeten worden. ${ }^{17}$ Kortom, de aangevoerde feiten en omstandigheden tasten de geldigheid van artikel 4 lid 4 gelezen in samenhang met artikel 2 sub k Verordening (EG) nr. 1099/2009 niet aan.

\section{Commentaar}

Toetsing aan de vrijheid van godsdienst

Het arrest Liga van Moskeeën raakt aan een zeer gevoelig onderwerp: de slacht van dieren volgens religieuze methoden en de vraag in hoeverre de godsdienstvrijheid daar bescherming aan biedt. De gevoeligheid bestaat er onder meer in dat een afweging moet worden gemaakt tussen de bescherming van een grondrecht dat vooral minderheidsgroeperingen zoals de islamitische en de joodse gemeenschappen in Europa raakt, en de bescherming van de publieke belangen van dierenwelzijn en de volksgezondheid. Het maken van een afweging tussen deze verschillende belangen kan ertoe leiden dat bepaalde bevolkingsgroepen worden 'gedehumaniseerd' als aan het dierenwelzijn een doorslaggevende betekenis wordt gehecht. ${ }^{18}$ Ook ligt een vorm van discriminatie en stigmatisering bij de beoordeling van deze kwestie op de loer, omdat het vooral de migrantengroepen in onze samenleving treft, zoals ook door de advocaat-generaal is opgemerkt. ${ }^{19}$

Van deze gevoeligheden blijkt uit de overwegingen die het Hof van Justitie aan de beantwoording van de prejudiciële vraag in dit arrest wijdt aan de oppervlakte weinig. Het Hof van Justitie beperkt zich in dit arrest formeel gezien tot de beantwoording van de vraag precies zoals die door de verwijzende rechter werd gesteld, namelijk of het Unierecht een ongerechtvaardigde inmenging op de godsdienstvrijheid maakt vanwege de eis dat het slachten van dieren moet plaatsvinden in een erkend slachthuis. Daarnaast beperkt het Hof van Justitie in dit arrest, zoals het zelf stelt, alleen tot de vaststelling of er wel sprake is van een beperking van de vrijheid van godsdienst. Zoals hierna wordt uitgelegd, doet het Hof van Justitie toch veel meer dan dat.

De advocaat-generaal wees er vooraf op dat er 'een onmogelijke afweging' zou moeten worden gemaakt over deze kwestie omdat daarin uiteindelijk een hiërarchie moet wordt aangebracht tussen de eerbiediging van de godsdienstvrijheid en het nastreven van doelstellingen van dierenwelzijn, voedselveiligheid en volksgezond-

17. Liga van Moskeeën, punten 81-83

18. A. Peters, 'De-humanisation? CJEU, Liga van Moskeeën en Islamitische Organisaties Provincie Antwerpen on Religious Slaughter', blogpost van 26 juni 2018 op www.ejiltalk.org

19. Conclusie van de A-G inzake Liga van Moskeeën, punt 106. 
heid. ${ }^{20}$ Ook waarschuwde de advocaat-generaal dat het Hof van Justitie zich maar niet zou moeten mengen in een theologisch debat over de draagwijdte van de religieuze verplichtingen tijdens het islamitische offerfeest. $^{21}$ Volgens de vereniging GAIA (Global Action in the Interest of Animals), die schriftelijke opmerkingen voor het Hof van Justitie indiende, zou het hier niet om een onaantastbare verplichting van het islamitische geloof gaan. ${ }^{22}$ Bepaalde vertegenwoordigers van de islamitische gemeenschap vinden dat een bepaalde vorm van verdoving voorafgaand aan de slacht toelaatbaar is volgens de islamitische geloofsvoorschriften. Het Hof van Justitie heeft het advies van de advocaat-generaal overgenomen en zich niet in deze kwestie gemengd. Het heeft aangenomen dat de godsdienstvrijheid van toepassing is. ${ }^{23}$ Het verwijst hiervoor naar een uitspraak van het Europees Hof voor de Rechten van de Mens (EHRM) dat zich al eerder over het slachten van dieren volgens de orthodoxe joodse gemeenschap heeft uitgelaten. ${ }^{24}$ Het Hof van Justitie herhaalt in het arrest dat het begrip 'godsdienst' ruim moet worden uitgelegd en zowel het forum internum (het feit een overtuiging te hebben), als het forum externum (de belijdenis van de godsdienst in het openbaar) omvat. Onder de godsdienstvrijheid valt daarmee ook de rituele slachting van dieren. ${ }^{25}$

Het Hof van Justitie heeft zich in het arrest verder, zoals al gezegd, ogenschijnlijk 'beperkt' tot de vaststelling óf er wel sprake is van een belemmering van de godsdienstvrijheid. Het gebruikt vrij veel overwegingen om daarover een negatief oordeel te vellen (punten 52-80). Het Hof van Justitie weegt hierin verschillende aspecten mee, waaronder of het vereiste van de slacht in een erkend slachthuis zonder onderscheid van toepassing is op alle organisatoren van dierenslachtingen, welke doelstellingen de Uniewetgever met de, door het Hof van Justitie genoemde, 'technische eisen' nastreeft, en het belang dat onder het Unierecht aan het dierenwelzijn wordt gehecht. Deze aspecten worden normaliter meegewogen om te bepalen of een beperking gerechtvaardigd kan worden. Strikt genomen zou het Hof van Justitie zich daar dus niet over hoeven uit te laten. Toch bespreekt het die elementen wel. Mogelijk heeft het Hof van Justitie het oordeel dat geen sprake is van een beperking van de godsdienstvrijheid zo extra kracht willen bijzetten. Hieruit blijkt, op minder expliciete wijze, toch de gevoeligheid van het onderwerp waar dit arrest over gaat.

Toch overtuigt het oordeel van het Hof van Justitie daarmee niet. Dat komt ten eerste omdat het Hof van Justitie een wat eenzijdig beeld geeft van de argumenten die in een zaak als deze zouden kunnen spelen. Juist de kwestie waar het om draait, namelijk óf de betrokken

20. Conclusie van de A-G inzake Liga van Moskeeën, punt 94.

21. Conclusie van de A-G inzake Liga van Moskeeën, punt 44.

22. Conclusie van de A-G inzake Liga van Moskeeën, punt 52.

23. Liga van Moskeeën, punten 43-45.

24. EHRM 27 juni 2000, nr. 27417/95, Cha'are Shalom Ve Tsedek/Frankrijk, ECLI:CE:ECHR:2000:0627JUD002741795, punt 74.

25. Liga van Moskeeën, punten 43-45. gemeenschappen en individuen werkelijk worden beperkt in de uitoefening van de vrijheid van hun religie, doordat het hun - in het extreme geval - onmogelijk werd gemaakt om aan dierlijk vlees te komen dat geslacht is volgens religieuze riten, wordt na lezing van het arrest eigenlijk niet duidelijk. Het Hof van Justitie bespreekt ook niet of er wellicht sprake kon zijn van een indirecte vorm van discriminatie op grond van geloof, dat wil zeggen, of de verplichtingen, hoewel neutraal geformuleerd, niet toch met name nadelige en mogelijk buitensporige gevolgen heeft voor een bepaalde geloofsgemeenschap. Zulke overwegingen komen wel naar voren in het arrest Cha're Shalom ve Tsedek t. Frankrijk van het EHRM, waarin het EHRM overigens evenmin een belemmering van de godsdienstvrijheid aannam. ${ }^{26}$ De wijze waarop het Hof van Justitie beoordeelt of sprake is van een belemmering van dit grondrecht is verklaarbaar doordat het zich in beginsel altijd richt op de gronden die door de partijen zijn aangevoerd. Het lastige daaraan is echter dat onduidelijk blijft welke maatstaf het nu precies hanteert om te bepalen wanneer de uitoefening van een grondrecht wordt belemmerd. Hoe verwaarloosbaar waren de extra kosten die gemaakt moesten worden om te voldoen aan de eisen voor slachtinrichtingen, en welke gevolgen heeft dit uiteindelijk voor de mogelijkheden om de godsdienstvrijheid uit te oefenen? Daar geeft het Hof van Justitie geen antwoord op. Het richt zich bij de beantwoording van de vragen eigenlijk meer op de uitoefening van de economische activiteiten door de slachtinrichtingen als zodanig, en daar hoort zoals blijkt uit het arrest logischerwijze bij dat kosten door de ondernemingen moeten worden gemaakt. $^{27}$

Ten tweede overtuigt het oordeel van het Hof van Justitie dat geen sprake is van een belemmering van de godsdienstvrijheid niet omdat het zich met name heeft gericht op de elementen die voorkomen in de toets van de rechtvaardiging van een belemmering. Daarbij vertrouwt het Hof van Justitie, gelet op de overwegingen die het daaraan wijdt, vrijwel blindelings op de keuze die de Uniewetgever heeft gemaakt om het dierenwelzijn en de volksgezondheid te bevorderen. De advocaatgeneraal wees er nog op dat het onverdoofd slachten onder goede omstandigheden juist minder pijnlijk kan zijn voor dieren dan wanneer er wel verdoving heeft plaatsgevonden. ${ }^{28}$ Ook wees de advocaat-generaal op de sterke industrialisering in deze sector die de stress en het lijden van dieren erg vergroot. ${ }^{29}$ Het Hof van Justitie bespreekt deze argumenten echter niet en uit geen twijfel over de geschiktheid van het vereiste van erkende slachthuizen om het dierenwelzijn, dan wel de volksgezondheid te bevorderen. Of het Hof van Justitie hiermee een 'volledige' toetsing heeft uitgevoerd van de afweging die de Uniewetgever al heeft gemaakt, wordt echter niet duidelijk, nu het alleen als conclusie aan deze overwe-

\footnotetext{
Cha'are Shalom Ve Tsedek/Frankrijk, punten 80-84.

Liga van Moskeeën, punt 77.

Liga van Moskeeën, punt 65

Conclusie van de A-G inzake Liga van Moskeeën, punten 106-109.
} 
gingen verbindt dat geen sprake is van een beperking van het grondrecht. Daarmee blijft de vraag open of eenzelfde beoordeling zal worden gegeven in mogelijke toekomstige gevallen waarin wel sprake zou zijn van een beperking van de godsdienstvrijheid en een rechtvaardiging zou moeten worden geboden. Mogelijk zal het Hof van Justitie ook in die gevallen geen indringende toetsing maken van de beoordeling die de Uniewetgever al heeft gemaakt, nu het zich daarvan in beginsel onthoudt als het gaat om technisch ingewikkelde beoordelingen die moeten worden gemaakt. ${ }^{30}$ De wijze waarop het Hof van Justitie de grondrechtelijke toetsing heeft uitgevoerd in deze zaak wekt vooralsnog verwarring, en het draagt zoals gezegd niet bij aan de overtuigingskracht van het uiteindelijke oordeel over de door de rechtbank voorgelegde kwestie.

Interne aangelegenheden van de lidstaten? Het Hof van Justitie heeft zich in dit arrest uitgelaten over maar een klein onderdeel van de discussie die wordt gevoerd over de ruimte die de uitoefening van de godsdienstvrijheid wordt gelaten en de vraag in hoeverre inmengingen daarop kunnen worden gerechtvaardigd. Het zal zich echter zeker bewust zijn geweest van de vragen waar de lidstaten gezien dit onderwerp mee worstelen. In verschillende lidstaten wordt gediscussieerd over de invoering van een algeheel verbod op het onverdoofd slachten van dieren, zonder uitzondering voor de rituele slacht. In meerdere lidstaten is al een algehele plicht aangenomen, zoals in Denemarken en inmiddels ook in België. ${ }^{31}$ In Nederland heeft de staatssecretaris van Economische Zaken in 2017 nog een convenant ondertekend waarin afspraken zijn gemaakt over het onbedwelmd slachten van dieren volgens religieuze riten. ${ }^{32}$ Het onverdoofd slachten van dieren volgens religieuze riten blijft daarmee dus wel toegestaan, maar er gelden verschillende beperkingen. Zo is de afspraak dat dieren binnen 40 seconden nadat de halssnede bij dieren is aangebracht, moeten worden bedwelmd om onnodig lijden te voorkomen. In maart van 2018 is door de Partij voor de Dieren een nieuw initiatiefvoorstel ingediend om verdergaande bescherming aan dieren te bieden door ook in Nederland een algehele plicht tot bedwelming van dieren voorafgaand aan de slacht in te voeren. ${ }^{33} \mathrm{Al}$ eerder werd een wetsvoorstel met dezelfde strekking ingediend. ${ }^{34}$ Opnieuw zal het parlement een afweging moeten maken tussen de eerbiediging van de godsdienstvrijheid tegenover, onder meer, het dierenwelzijn. Het Hof van Justitie heeft zich, zoals in het vorige punt

30. Zie bijv. HvJ 22 mei 2014, zaak C-356/12, Glatzel, ECLI:EU:C: 2014:350, punt 52 .

31. In België gaat het om Decreet 1213 2016/17, houdende wijziging van de wet van 14 augustus 1986 betreffende de bescherming en het welzijn van dieren, wat de toegelaten methodes voor het slachten van dieren betreft.

32. Addendum bij het convenant onbedwelmd slachten volgens religieuze riten, nr. WJZ/17085228, als overeengekomen op 5 juli 2017, Stcrt. 2017, 41228.

33. Voorstel van Wet van het lid Thieme tot wijziging van de Wet dieren in verband met de invoering van een algehele plicht tot bedwelming van dieren voorafgaand aan de slacht, Kamerstukken II 2017/18, 34908, 2.

34. Zie ook Kamerstukken I/ 2007/08, 31571, 3. uiteen is gezet, niet volledig en in ieder geval niet door middel van een indringende toetsing, over deze afweging uitgelaten.

In de discussies over het invoeren van een algeheel verbod van de onverdoofde slacht van dieren is de vraag wel relevant hoe een dergelijk verbod zich precies verhoudt tot het Unierecht. ${ }^{35}$ Zoals in het arrest aan de orde is geweest, moeten de lidstaten op grond van artikel 4 lid 4 Verordening (EG) nr. 1099/2009 een uitzondering maken op de verplichting tot bedwelming van dieren voorafgaand aan de slacht wanneer dieren worden geslacht volgens de speciale methoden die vereist zijn voor religieuze riten. Een andere relevante bepaling van deze verordening die in het arrest niet aan de orde kwam, is artikel 26 lid 2 sub c, dat bepaalt dat de lidstaten nationale voorschriften mogen aannemen die strekken tot uitgebreidere bescherming van dieren bij het doden van dieren, waar het gaat om 'het slachten, en daarmee verband houdende activiteiten, van dieren overeenkomstig artikel 4, lid 4'. Biedt deze bepaling nu de mogelijkheid aan lidstaten om alsnog af te zien van de uitzondering op het onbedwelmd slachten van dieren, of moeten zij 'overeenkomstig artikel 4, lid 4' vasthouden aan de door de Uniewetgever gemaakte uitzondering waarmee aan de godsdienstvrijheid van bepaalde religieuze minderheden in Europa bescherming moet worden geboden? De bepalingen van de verordening bieden hierover geen volstrekt helder antwoord. Evenmin bieden de overwegingen die in de verordening voorafgaan aan de bepalingen dat. Daarin wordt gewezen op de bestaande diversiteit in de omzetting door de lidstaten van de communautaire regels over religieus slachten van dieren. ${ }^{36}$ Ook wordt benadrukt dat het van belang is dat de uitzondering op het bedwelmen voorafgaand aan het slachten gehandhaafd blijft en dat de lidstaten hierin een mate van subsidiariteit behouden. In het arrest Liga van Moskeeën zegt het Hof van Justitie hierover dat de Uniewetgever zich positief heeft ingespannen om de vrijheid van godsdienst te eerbiedigen door een uitzondering te maken op de verplichting tot bedwelming voorafgaand aan de slacht voor religieuze riten. ${ }^{37}$ Het lijkt er daarmee op dat de lidstaten gehouden zijn een uitzondering te maken op de bedwelmde slacht van dieren voor de religieuze riten.

35. Voor een analyse van de toelaatbaarheid van het Deense verbod in het licht van het EVRM, zie G. van der Schyff, 'Onverdoofd ritueel slachten getoetst aan het EVRM: het Deense verbod als Europees vraagstuk', Tijdschrift voor Religie, Recht en Beleid 2015, afl. 1, p. 54-65.

36. In overweging 18 is opgenomen dat '(...) de communautaire voorschriften die van toepassing zijn op religieus slachten, afhankelijk van de nationale contexten verschillend zijn omgezet en gezien het feit dat in de nationale regels rekening wordt gehouden met dimensies die verder gaan dan het doel van deze verordening, is het van belang dat de uitzondering op het bedwelmen voorafgaand aan het slachten gehandhaafd blijft; hierbij behouden de lidstaten echter een bepaalde mate van subsidiariteit. Deze verordening respecteert derhalve de vrijheid van godsdienst, evenals het recht voor iedereen om zijn godsdienst te belijden of overtuiging tot uitdrukking te brengen in erediensten, in onderricht, in de praktische toepassing ervan en in het onderhouden van geboden en voorschriften zoals verankerd in artikel 10 van het Handvest van de grondrechten van de Europese Unie.'

37. Liga van Moskeeën, punt 56. 
Tegelijkertijd komt dit niet overeen met de praktijk, nu verschillende lidstaten al een algeheel verbod hebben ingevoerd. Het Hof van Justitie heeft zich over de verhouding daarvan tot het Unierecht in het arrest Liga van Moskeeёn niet kunnen buigen. Wel heeft het duidelijk gemaakt dat de ruimte voor de nationale wetgevers om volgens het nationale recht verdergaande bescherming te bieden voor de bevordering van het dierenwelzijn door het Unierecht 'beperkt' is doordat het slachten van dieren, ook wanneer religieuze slachtmethoden worden toegepast, in een erkend slachthuis dient plaats te vinden. Verder is uit het arrest Liga van Moskeeёn duidelijk geworden dat de lidstaten artikel 10 van het Handvest dienen te eerbiedigen wanneer zij maatregelen treffen ter regulering van de rituele slacht van dieren. ${ }^{38}$ Het Hof van Justitie heeft immers bepaald dat de speciale slachtmethoden die vereist zijn voor religieuze riten binnen de werkingssfeer van Verordening (EG) nr. 1099/2009 en artikel 10 van het Handvest vallen.

Opvallend hierbij is dat verschillende lidstaten en de Europese Commissie voor het Hof van Justitie nog wel hadden aangevoerd dat de kwestie waarover de Belgische rechter een prejudiciële vraag stelde om interne aangelegenheden van de lidstaten gaat, en dat de vraag niet-ontvankelijk moest worden verklaard. ${ }^{39}$ Het Hof van Justitie wijst er echter op dat de brief die door de minister was rondgezonden over het verbod op de tijdelijke slachtinrichtingen was gebaseerd op artikel 4 lid 4 Verordening (EG) nr. 1099/2009. De vraag die door de Belgische rechter werd gesteld, was dus wel degelijk relevant voor de beslechting van het geschil, en werd daarom ontvankelijk verklaard. ${ }^{40}$ Hieruit, en uit het vervolg van het arrest, kan worden afgeleid dat de lidstaten wanneer zij maatregelen nemen met betrekking tot de religieuze slacht het Unierecht ten uitvoer brengen en dus binnen de reikwijdte van het Unierecht handelen. De kwestie van het rituele slachten is geen exclusieve interne aangelegenheid van de lidstaten. Zij dienen met de hiervoor genoemde beperkingen van het Unierecht rekening te houden, maar het is zoals uit het voorgaande blijkt lastig om in te schatten welke ruimte het Unierecht precies biedt voor verdergaande bescherming van het dierenwelzijn bij het doden van dieren.

\section{Tot slot: Unierechtelijke uniformiteit en de}

bescherming van grondrechten

Hoewel het arrest Liga van Moskeeën en Verordening (EG) nr. 1099/2009 nog wel wat vragen oproepen, is in ieder geval duidelijk dat de bescherming van de rituele slacht van dieren een belangrijke Unierechtelijke dimen-

38. Lidstaten mogen echter wel een verdergaande bescherming van de nationale godsdienstvrijheid bieden op grond van art. 53 van het Handvest, waarvan het Hof van Justitie heeft gezegd dat 'het de nationale rechterlijke instanties blijft vrijstaan de nationale grondrechtenbescherming toe te passen, mits daardoor het beschermingsniveau van het Handvest, zoals door het Hof uitgelegd, en de voorrang, eenheid en werking van het recht van de Unie niet in het gedrang komen'. Zie daarvoor HvJ 26 februari 2013, zaak C-399/11, Melloni, ECLI:EU:C: 2013:107, punt 60 .

39. Liga van Moskeeën, punten 28 en 32.

40. Zie Liga van Moskeeën, punten 29 en 34-35. sie heeft. ${ }^{41}$ De Unierechtelijke wetgever heeft bij het vaststellen van de eisen die worden gesteld aan het slachten van dieren een afweging gemaakt tussen de bescherming van de vrijheid van godsdienst, de bescherming van het dierenwelzijn en de bescherming van de volksgezondheid, waar de lidstaten rekening mee moeten houden. Maar waarom wordt deze kwestie nu precies door het Unierecht gereguleerd en in welke mate blijft er ruimte over om op nationaal niveau verdergaande bescherming te bieden? Uit de overwegingen voorafgaand aan de bepalingen van Verordening (EG) nr. $1099 / 2009$ blijkt onder meer dat uniforme regels gewenst waren om de grote bezorgdheid van de consument over het dierenwelzijn weg te nemen en eveneens de (eerlijke) mededinging tussen bedrijfsexploitanten te verzekeren. ${ }^{42}$ Ook is de bescherming van dieren bij het doden blijkens die overwegingen van belang, omdat het van invloed is op de houding van de consument tegenover landbouwproducten, het de vleeskwaliteit en indirect ook de veilige arbeidsomstandigheden in slachthuizen verbetert. ${ }^{43}$ Het gaat hierbij dus om verschillende belangen die in sterke mate samenhangen met de internemarktdoelstelling van de Unie. Het is daarmee dus logisch dat het doden van dieren Unierechtelijk is gereguleerd.

Het Hof van Justitie heeft in het arrest Liga van Moskeeen verder verhelderd dat de Uniewetgever in Verordening (EG) nr. 1099/2009 een verplichte uitzondering op de bedwelming van dieren bij de slacht heeft gemaakt om (ook) de godsdienstvrijheid te eerbiedigen. In welke mate heeft de Uniewetgever echter ook uniformiteit beoogd te bewerkstelligen in de regulering van de godsdienstvrijheid bij het slachten van dieren? Zouden de lidstaten niet zelf, gelet op het beginsel van subsidiariteit, betere keuzes kunnen maken om de godsdienstvrijheid gezien de nationale situatie te eerbiedigen? Daarop geeft het Hof van Justitie verder geen antwoord. Eerder werd in een richtlijn nog aan de lidstaten de vrijheid gelaten om andere keuzes te maken met het oog op religieuze riten. ${ }^{44}$ De verordening schrijft echter als uitgangspunt een uitzondering voor de religieuze riten voor. Heeft de Uniewetgever daarmee dan bewust beoogd bescherming te bieden aan de religieuze gemeenschappen in Europa puur en alleen omdat deze gemeenschappen als minderheid bedreigd kunnen worden in de uitoefening van hun godsdienstvrijheid? Of hangt deze bescherming (enkel en alleen) samen met de doelstelling van de Uniewetgever om uniforme regels te stellen vanwege de wens om een goed functionerende interne markt te bewerkstelligen? ${ }^{45}$ Juist doordat het Hof van Justitie in het arrest Liga van Moskeeёn zich

41. In het arrest speelde ook nog Protocol nr. 33 betreffende de bescherming en het welzijn van dieren een rol van betekenis, omdat daarin het belang van het welzijn van dieren tot uiting komt.

42. Overweging 3 van Verordening (EG) nr. 1099/2009.

43. Overweging 4 van Verordening (EG) nr. 1099/2009.

44. Zie art. 4 Richtlijn 74/577/EEG van de Raad van 4 juni 1974 betreffende de verdoving van dieren voor het slachten, PbEG 1974, L 316/10.

45. De Uniewetgever kan aldus verschillende doelstellingen nastreven met uniforme regels over de uitoefening van grondrechten, zie daarover verder M. Beijer, Limits of fundamental rights protection by the EU: 
heeft beperkt tot de vraag die de verwijzende rechter stelde, heeft het Hof van Justitie zich over deze ingewikkelde vraag ook niet uit hoeven laten. Uniforme regels kunnen vanwege de verschillende genoemde doelstellingen, en vanwege de bescherming van grondrechten in Europa, gewenst zijn. De vraag blijft alleen of het Hof van Justitie en de Uniewetgever dit uitgangspunt waar het gaat om de vrijheid van de godsdienst, die in de lidstaten op zeer verschillende wijze wordt gereguleerd, in toekomstige gevallen misschien toch zullen moeten verlaten nu de lidstaten daarin geen uniforme benadering laten zien. 